\title{
Controle de Rhizoctonia solani e Fusarium oxysporum f.sp. phaseoli por biopreparados de isolados de Trichoderma spp.
}

\author{
Pedro Paulo Dias ${ }^{1}$, Ricardo Luis Louro Berbara² Maria do Carmo de Araújo Fernandes $^{3}$
}

\begin{abstract}
${ }^{1}$ Engenheiro Agrônomo, DSc., UFRRJ, Rua Ipitangas, Lote 9, Quadra 10. Bairro Magalhães Bastos, Rio de Janeiro/RJ, CEP: 21.745-400. ${ }^{2}$ Engenheiro Agrônomo, PhD. Professor Associado III, UFRRJ, Departamento de Solos. ${ }^{3}$ Bióloga, Ph.D., Pesquisadora da PESAGRO-RIO/ Centro Estadual de Pesquisa em Agricultura Orgânica (CEPAO). Autor para correspondência: Pedro Paulo Dias (diaspp@bol.com.br) Data de chegada: 10/07/2012. Aceito para publicação em: 01/10/2013.
\end{abstract}

\section{RESUMO}

Dias, P.P.; Berbara, R.L.L.; Fernandes, M.C.A. Controle de Rhizoctonia solani e Fusarium oxysporum f.sp. phaseoli por biopreparados de isolados de Trichoderma spp. Summa Phytopathologica, v.39, n.4, p.258-262, 2013.

Os experimentos objetivaram avaliar em condições de casa de vegetação o biocontrole dos fitopatógenos Rhizoctonia solani (RS) e Fusarium oxysporum f.sp. phaseoli (FOP) em alface (Lactuca sativa L.) cultivar Regina, e feijão-vagem (Phaseolus vulgaris L.) cultivar Alessa, respectivamente, utilizando como agentes antagonistas, 10 isolados de Trichoderma spp. selecionados em testes in vitro. Foram feitos biopreparados à base de arroz previamente colonizado por isolados de Trichoderma spp. e posteriormente triturados. Para a realização dos testes, os biopreparados foram inoculados previamente na proporção de $10^{9}$ conídios.mL-1, em substrato comercial para produção de mudas. Após sete dias, os patógenos foram introduzidos separadamente em duas concentrações distintas: $R$. solani na proporção de $144 \mathrm{mg}$ de meio de arroz por kg de substrato e $F$. oxysporum f.sp. phaseoli inoculado na forma de suspensão contendo $4,75 \times 10^{6}$ conídios. $\mathrm{mL}^{-1}$. Avaliou-se a influência dos biopreparados na $\%$ de damping-off de pós-emergência em plantas de alface e a severidade de murcha em plantas de feijão-vagem. O biopreparado referente ao isolado T-03 foi o mais eficiente no controle de $R$. solani em plantas de alface cultivar Regina, por ter reduzido a incidência de damping-off de pós-emergência nessa cultura. Por outro lado, nenhum dos biopreparados apresentou efeito antagonista satisfatório à $F$. oxysporum f.sp. phaseoli em plantas de feijão-vagem.

Palavras-chave adicionais: Biocontrole, antagonistas, patógenos do solo.

\section{ABSTRACT}

Dias, P.P.; Berbara, R.L.L.; Fernandes, M.C.A. Rhizoctonia solani and Fusarium oxysporum f.sp. phaseoli control by biopreparation with Trichoderma spp. isolates. Summa Phytopathologica, v.39, n.4, p.258-262, 2013.

The experiments aimed to evaluate under greenhouse conditions the biocontrol of plant pathogens Rhizoctonia solani (RS) and Fusarium oxysporum f.sp. phaseoli (FOP) in lettuce (Lactuca sativa L.) cultivar Regina and in common bean (Phaseolus vulgaris L.) cultivar Alessa, respectively, using as antagonistic agents 10 Trichoderma spp. isolates selected from in vitro tests. Inoculants were prepared with rice previously colonized by Trichoderma spp. and subsequently ground. For the tests, the antagonists were previously inoculated at a ratio of $10^{9}$ conidia $\mathrm{mL}^{-1}$ on commercial substrate for seedling production. Following seven days, the pathogens were separately introduced at two different concentrations: $R$. solani at a ratio of $144 \mathrm{mg}$ rice medium per $\mathrm{kg}$ of substrate and $F$ oxysporum f.sp. phaseoli inoculated as a suspension containing $4.75 \times 10^{6}$ conidia $\mathrm{mL}^{-1}$. The influence of antagonists on $\%$ post-emergence damping-off in lettuce and the severity of wilt in common beans were evaluated. The biopreparation with T-03 isolate was most effective in controlling $R$. solani in lettuce cultivar Regina, for having reduced the incidence of post-emergence damping-off in this culture. On the other hand, none of the biopreparations showed satisfactory antagonistic effect on $F$. oxysporum f.sp. phaseoli in common bean plants.

Additional keywords: Biocontrol, antagonists, soil-borne pathogens

Os fungos das espécies Rhizoctonia solani Kuhn e Fusarium oxysporum Schlecht. f.sp. phaseoli Kendrick \& Snyder são classificados como fungos imperfeitos, segundo Moreira e Siqueira (17) pertencentes à divisão Deuteromycota, cujos fungos são popularmente denominados deuteromicetos, vivendo no solo saprofiticamente ou exercendo parasitismo sobre diversas culturas anuais ou perenes, animais e outros fungos presentes neste ambiente. A ação desses fungos está relacionada aos sintomas de tombamento de plântulas e podridão de raiz de plantas (13).

Rhizoctonia solani, geralmente, é encontrado na forma micelial, pois não produz esporos e utilizam como forma de sobrevivência no solo a formação de estruturas globulosas denominadas escleródios ou esclerócios (9) que podem sobreviver no solo por, no mínimo, um ano (20).

Já Fusarium oxysporum f.sp. phaseoli, de acordo com Bianchini et al. (7), é uma espécie de fungo que atua invadindo frequentemente 
as pontas das raízes, podendo penetrar no hospedeiro por aberturas naturais, como verticelas, ou ferimentos.

Segundo Bedendo (4), damping-off é um grupo de doença que incide em tecidos vegetais jovens, em sementes recém plantadas que apodrecem, devido à ação de patógenos presentes no solo ou veiculados na semente, ocorrendo antes da germinação e após o entumescimento deste órgão, reduzindo o "stand" inicial de plantas no viveiro de produção de mudas ou no campo, sendo popularmente chamado de tombamento.

Conforme esse autor, quando o ataque do patógeno ocorre após a emergência das plântulas essa doença é denominada como dampingoff de pós-emergência, cujos sintomas são observados na região do colo nas plântulas, rente ao solo, com o aparecimento de manchas encharcadas que com o tempo vão evoluindo para lesões profundas, culminando com a constrição (contração) do caule, que por estar enfraquecido, tende a tombar.

As doenças vasculares ou "murchas", de acordo com Bedendo (5), são aquelas onde o patógeno provoca danos ao sistema de transporte de seiva bruta (vasos xilemáticos), impedindo com isso a translocação de água e nutrientes absorvidos pela planta. Como sintomas reflexos, em plantas adultas ocorrem clareamento das nervuras das folhas e mudança da tonalidade verde desse órgão que paulatinamente vai amarelecendo. Estes sintomas progridem das folhas mais velhas para as folhas mais jovens, podendo gradativamente promover a murcha das folhas ou brotos, necrose das bordas foliares, senescência de folhas, flores e frutos, a produção de raízes adventícias e, no último estádio, a destruição da planta.

Patógenos que provocam doenças vasculares, segundo esse autor, são mais evoluídos que aqueles relacionados ao damping-off e podridão de raízes, pelo fato dos primeiros serem específicos tanto em termos de hospedeiro, quanto ao tecido que infectam e portanto, a classificação desses agentes chega ao grau de raças fisiológicas.

De acordo com Lima et al. (11), o controle biológico ou biocontrole é fundamentado nas interações antagônicas que ocorrem entre as espécies. O emprego de isolados do fungo Trichoderma Persoon ex Fries, também um deuteromiceto, é uma das alternativas aos produtos químicos para o combate de fitopatógenos de solo e em sementes (15).

Segundo Benítez et al. (6), determinadas espécies de Trichoderma interferem na vida do fitopatógeno por diversos mecanismos de ação como a competição por espaço e nutrientes, a antibiose, o micoparasitismo, a fungistase, a indução de resistência, entre outros. Entre os agentes de biocontrole, os mais importantes são os do gênero Trichoderma por serem antagonistas eficazes de uma ampla faixa de fungos fitopatogênicos, como, por exemplo, Rhizoctonia solani, Sclerotium rolfsii, Sclerotinia sclerotiorum, Fusarium spp. e Pythium spp. (16)

Assim testou-se, em condições de casa de vegetação, o controle biológico dos patossistemas $R$. solani - alface cultivar Regina e $F$. oxysporum f.sp. phaseoli - feijão-vagem cultivar Alessa com o emprego de isolados de Trichoderma spp..

\section{MATERIAL E MÉTODOS}

\section{Localização da Área de Estudo}

Os testes foram realizados no laboratório de Biologia do Solo da UFRRJ e em casa de vegetação do Centro Estadual de Pesquisa em Agricultura Orgânica da PESAGRO-RIO (CEPAO/PESAGRO-RIO).

O ensaio referente ao biocontrole de Rhizoctonia solani em alface, ocorreu no período de julho a setembro de 2010 e o teste com Fusarium oxysporum f.sp. phaseoli foi realizado de dezembro de 2010 a fevereiro de 2011.

Obtenção e preparação de isolados de Trichoderma spp. e de fitopatógenos para uso em testes de controle biológico

Os isolados de Trichoderma spp. utilizados neste trabalho pertencem a micoteca do CEPAO/PESAGRO-RIO, município de Seropédica/RJ, que foram coletados de amostras de solo do Sistema Integrado de Produção Agroecológica (SIPA), também conhecido como Fazendinha Agroecológica km 47 (1), situado no mesmo município, além de amostras oriundas das cidades de Paraty e Paty do Alferes, do estado do Rio de Janeiro. Os isolados dos patógenos de solo foram obtidos a partir de plantas infectadas com Rhizoctonia solani na cultura da alface e Fusarium oxysporum f.sp. phaseoli no feijoeiro-comum, Tabela 1.

Todos os isolados obtidos foram conservados em tubos de ensaio contendo meio de cultura BDA e óleo mineral até a realização dos experimentos.

Inicialmente, os isolados foram repicados para o meio de cultura (Batata-Dextrose-Ágar) (BDA) Difco, contendo 0,3 g.L.-1 de

Tabela 1. Origem de isolados de Trichoderma spp., Fusarium oxysporum f.sp. phaseoli e Rhizoctonia solani utilizados nos testes in vivo em condições de casa de vegetação

\begin{tabular}{|c|c|c|c|}
\hline Isolados & Local de coleta & Município & Ano do isolamento \\
\hline Trichoderma sp.(T-02) & Fazendinha Agroecológica km 47 & Seropédica (RJ) & 2005 \\
\hline Trichoderma sp.(T-03) & Fazendinha Agroecológica km 47 & Seropédica (RJ) & 2005 \\
\hline Trichoderma sp.(T-04) & Fazendinha Agroecológica km 47 & Seropédica (RJ) & 2005 \\
\hline Trichoderma sp.(T-05) & Fazendinha Agroecológica km 47 & Seropédica (RJ) & 2005 \\
\hline Trichoderma sp.(T-06) & Fazendinha Agroecológica km 47 & Seropédica (RJ) & 2005 \\
\hline Trichoderma sp.(T-07) & Fazendinha Agroecológica km 47 & Seropédica (RJ) & 2005 \\
\hline Trichoderma sp.(T-08 & Propriedade particular & Paraty (RJ) & 2005 \\
\hline Trichoderma sp.(T-10) & PESAGRO-RIO/EES & Seropédica (RJ) & 2005 \\
\hline Trichoderma sp.(T-11) & Fazendinha Agroecológica km 47 & Seropédica (RJ) & 2005 \\
\hline Trichoderma sp.(T-12) & PESAGRO-RIO/CEA & Paty do Alferes (RJ) & 2006 \\
\hline Rhizoctonia solani $(\mathrm{RS})$ & Propriedade particular & Nova Friburgo (RJ) & 2008 \\
\hline Fusarium oxysporium f. sp. phaseoli(FOP) & Fazendinha Agroecológica km 47 & Seropédica (RJ) & 2008 \\
\hline
\end{tabular}


cloranfenicol e incubados em $\mathrm{BOD} \mathrm{a} 25^{\circ} \mathrm{C}$ de temperatura, fotoperíodo de 12 horas de luz por 7 dias.

Para a produção de biopreparados de Trichoderma spp. foi feito inicialmente transferência de três discos de micélio de $8,0 \mathrm{~mm}$ de diâmetro do meio de cultura BDA para substrato constituído de 60 $\mathrm{g}$ de arroz umedecido com água destilada (70 \% p/v), acondicionados em sacos de polietileno de $20,5 \times 12,0 \mathrm{~cm}$, e autoclavados por 30 minutos a $120^{\circ} \mathrm{C}(1 \mathrm{~atm})$, segundo metodologia descrita por Lohmann et al. (12), com modificações. Os materiais foram colocados em BOD a $25^{\circ} \mathrm{C}$, e fotoperíodo de 12 horas de luz, sendo revolvidos diariamente até se obter colonização uniforme e total dos fungos no substrato. Seguiu-se a mesma metodologia para multiplicação de R. solani.

Após sete dias, os substratos colonizados foram transferidos para sacos de papel e colocados para secagem em temperatura ambiente. Em seguida, os materiais secos foram moídos em um triturador e peneirados, obtendo-se assim os biopreparados de Trichoderma spp. e o inóculo de $R$. solani.

A concentração da suspensão de conídios dos biopreparados foi determinada em $10^{9}$ conídios. $\mathrm{mL}^{-1}$ por $10 \mathrm{~g}$ de substrato de plantio (comercial), segundo De Cal et al. (8). Já para $R$. solani, foi adotada concentração citada por Santos et al. (22) que utilizaram a dosagem de $144 \mathrm{mg}$ de inoóculo. $\mathrm{kg}^{-1}$ de substrato de plantio.

Para F. oxysporum f.sp. phaseoli foi preparada suspensão de conídios obtida de culturas puras do patógeno, a partir de colônias crescidas em meio de cultura BDA. A concentração final foi determinada em $4,75 \times 10^{6}$ conídios. $\mathrm{mL}^{-1}$ por meio de contagens em câmara de Neubauer.

\section{Preparo de substrato para implantação dos experimentos}

O substrato comercial Holambra ${ }^{\circledast}$ utilizado nos testes foi inicialmente esterilizado por meio de autoclavagem, a $120^{\circ} \mathrm{C}(1 \mathrm{~atm})$ por 30 minutos. Após, foi distribuído em quantidades iguais em bandejas de alumínio medindo $22 \times 17$ × $3 \mathrm{~cm}$ que representavam os dois experimentos.

Na sequência, foi feita a inoculação dos biopreparados de Trichoderma spp. na concentração de $10^{9}$ conídio.mL. Sete dias após, realizou-se a inoculação de $R$. solani e F.oxysporum f.sp. phaseoli, de acordo com os experimentos. Os inóculos foram preparados em 100 $\mathrm{mL}$ de água destilada autoclavada, e misturados superficialmente ao substrato de cada bandeja e posteriormente, as mesmas foram colocadas em casa de vegetação.

Nos experimentos foram consideradas duas testemunhas, a saber: na primeira, realizou-se a aplicação de água destilada diretamente no substrato comercial e na testemunha adicional, o substrato foi inoculado com o patógeno referente a cada um dos testes realizados.

Experimento 1: Influência de biopreparados de Trichoderma spp. no controle de Rhizoctonia solani (RS) em plantas de alface cv. Regina

Para a realização deste teste foram utilizados biopreparados dos antagonistas referente aos seguintes isolados: T-02, T-03, T-06, T07, T-08, T-11 e T-12 e a inoculação dos mesmos foi realizada como já citado anteriormente. A testemunha principal consistiu em substrato sem microrganismos, e a testemunha adicional correspondeu à inoculação de $R$. solani no substrato de plantio.

Após quatro dias da inoculação de $R$. solani, realizou-se o plantio de sementes de alface cv. Regina. A partir da emergência das plantas, foram iniciadas as avaliações de tombamento de plantas que apresentavam sintomas típicos de damping-off de pós-emergência.
E para o cálculo da \% de tombamento (\% T-PÓS) foi usada a fórmula modificada por Nawar (19).

\% T-PÓS = (Número de plântulas tombadas/Número de plântulas emergidas) x 100

Experimento 2: Influência de biopreparados de Trichoderma spp.no controle de Fusarium oxysporum f.sp. phaseoli (FOP) em plantas de feijão-vagem cv. Alessa

Foram testados, na forma de biopreparados, os seguintes isolados de Trichoderma spp: T-04, T-05, T-06, T-07, T-08, T-10, T-12. Após quatro dias da inoculação de $F$. oxysporum f.sp. phaseoli realizou-se o plantios de sementes de feijão-vagem cultivar Alessa.

Da mesma forma que o experimento anterior, as avaliações foram iniciadas após a emergência das plantas. Nesse caso, foram identificadas plantas com sintomas de murcha e foi determinada a severidade de doença a partir de escala de notas elaborada pelo Centro Internacional de Agricultura Tropical (CIAT) (13), onde a nota 1 representa plantas sem sintomas visíveis de murcha; 3 - Poucas folhas murchas (1 a 3) que representam $10 \%$ ou mais de folhagem, sintoma acompanhado de descoloração vascular limitada aos tecidos radiculares e ao hipocótilo; 5 -Aproximadamente $25 \%$ das folhas e hastes com murcha e clorose; 7 -Aproximadamente $50 \%$ de folhas e hastes com murcha, clorose e necrose limitadas; planta com nanismo; 9 - Plantas mortas ou severamente infectadas com $75 \%$ da folhagem e ramos com murcha, nanismo severo, clorose ou necrose com queda prematura.

O delineamento experimental adotado nos experimentos foi o de blocos ao acaso com cinco repetições por tratamento. Para a comparação entre as médias dos tratamentos, foi empregado o Teste de Scott-Knot ao nível de $5 \%$ de probabilidade, utilizando o programa estatístico SISVAR.

\section{RESULTADOS E DISCUSSÃO}

Quanto ao controle de R. solani referente ao Experimento 1, observa-se diferença significativa da \% de tombamento de plantas de alface (damping-off de pós-emergência) (Tabela 2), onde o isolado T03 se equiparou à testemunha 1 que não foi inoculada, e quando se compara os resultados deste isolado com a média da testemunha 2 (adicional) que foi inoculada com o patógeno observa-se redução da incidência da doença em 86,3\%.

Todavia os demais isolados de Trichoderma spp. se assemelharam estatisticamente ao percentual de tombamento da testemunha inoculada (adicional).

Em um experimento Lucon et al. (14) detectaram isolados de $T$. hamatum (IB08, IB30, IB60), T. harzianum (IB34,IB35), T. atroviride (IB13), T. spirale (IB16, IB24) e T. asperellum (IB44) eficientes no controle de $R$. solani, agente causal do tombamento em plântulas de pepino (Cucumis sativus L.) em casa de vegetação.

Em um ensaio realizado por Lewis \& Lumsden (10) foram identificados isolados de T. hamatum (TRI-4) e T. virens (Gl-3) que apresentaram eficiência na redução da incidência de damping-off causado por $R$. solani (R-23), em abóbora, berinjela, pepino e repolho.

De acordo com os resultados obtidos no Experimento 2 observase que não houve diferença significativa entre as médias dos tratamentos (Tabela 3). Entretanto, na comparação dessas médias com a testemunha 2 (adicional), destaca-se o biopreparado T-06 que reduziu em 43,4\% a severidade de murcha em plantas de feijão-vagem ocasionada por $F$. oxysporum f.sp. phaseoli (FOP).

Resultados semelhantes observaram Avendaño \& Rondon (3) que 
Tabela 2. Controle biológico de Rhizoctonia solani em alface cultivar Regina, por biopreparados de isolados de Trichoderma spp. expresso em \% de tombamento de plantas (damping-off de pós-emergência).

\begin{tabular}{lcc}
\hline Tratamentos & Tombamento de plantas & $\begin{array}{c}\text { Médias } \\
\text { transformadas }\end{array}$ \\
\hline Testemunha $\mathbf{\%}$ & 1,38 a 1,444 \\
T-03 x RS & 7,48 a1 & 2,336 \\
T-07 x RS & 37,64 a2 & 5,320 \\
T-02 x RS & 43,94 a2 & 5,814 \\
T-11 x RS & 40,05 a2 & 6,052 \\
T-12 x RS & 43,83 a2 & 6,488 \\
Testemunha & 54,70 a2 & 7,148 \\
(adicional) & & \\
T-08 x RS & 61,18 a2 & 7,536 \\
T-06 x RS & 72,43 a2 & 8,354 \\
\hline CV $(\%)$ & & 44,85 \\
\hline
\end{tabular}

Na coluna, as letras iguais correspondem a médias não significativas pelo teste de ScottKnot a $5 \%$ de probabilidade.

(1)- Os dados foram transformados em $\sqrt{\mathrm{x}+1}$

Tabela 3. Influência de tratamentos com biopreparados de isolados de Trichoderma spp. (T) na severidade de murcha em plantas de feijãovagem cultivar Alessa, ocasionado por Fusarium oxyspirum f.sp. phaseoli (FOP)

\begin{tabular}{|c|c|c|}
\hline Tratamentos & $\begin{array}{l}\text { Severidade de doença } \\
\text { (murcha) (Notas) }\end{array}$ & $\begin{array}{c}\text { Médias } \\
\text { transformadas }^{1}\end{array}$ \\
\hline Testemunha 1 & 1,64 a1 & 1,618 \\
\hline T-06 x FOP & 1,93 a1 & 1,706 \\
\hline T-05 x FOP & 2,14 a1 & 1,772 \\
\hline T-04 x FOP & 2,22 a 1 & 1,778 \\
\hline T-12 x FOP & 2,76 a1 & 1,886 \\
\hline T-10 x FOP & 3,10 a1 & 1,944 \\
\hline T-07x FOP & 3,24 a1 & 2,002 \\
\hline $\begin{array}{l}\text { Testemunha } 2 \\
\text { (adicional) }\end{array}$ & 3,42 a 1 & 2,056 \\
\hline T-08 x FOP & 3,70 a1 & 2,122 \\
\hline CV (\%) & & 23,43 \\
\hline
\end{tabular}

Na coluna, as letras iguais correspondem a médias não significativas pelo teste de ScottKnot a $5 \%$ de probabilidade.

(1)- Os dados foram transformados em $\sqrt{\mathrm{x}+1}$

também não obtiveram sucesso no biocontrole de Fusarium oxysporum f. sp. phaseoli em feijão da cultivar ICA Tundama, a partir de isolados de Trichoderma sp..

Entretanto, Nashwa et al. (18) detectaram redução da incidência de "Murcha de Fusarium" em feijão cultivar Giza 3 com o uso de formulações à base de T. harzianum, T. viride e T. spirale que atingiram, em média, as notas 3,7;4,1 e 5,2, respectivamente, enquanto que para a testemunha infectada somente com FOP foi atribuída nota 8,0. Ainda sobre esse trabalho, embora havendo decréscimo na incidência da doença, os valores das médias das notas foram superiores aos encontrados nesse experimento.

Em um ensaio similar, Alwathnani et al. (2) também identificaram decréscimo dos níveis dessa doença em plântulas de feijão-comum, com a inoculação do substrato com fungos incluindo T. harzianum e T. viride.
Finalmente, Poddar et al. (12) detectaram a eficiência de isolados T. viride e T. harzianum no biocontrole de murcha em grão de bico ocasionada por F. oxysporum f. sp. ciceris.

Pelos resultados alcançados no experimento 1 , cita-se o biopreparado obtido do isolado T-03 de Trichoderma spp. como eficiente no controle biológico de $R$. solani que ocasiona damping-off de pós-emergência em plantas de alface.

No outro experimento realizado, identifica-se o biopreparado (T06) de Trichoderma spp. como promissor para o controle de F. oxyspirum f.sp. phaseoli em feijão-vagem.

\section{AGRADECIMENTOS}

- À CAPES pela concessão da bolsa

- Ao Laboratório de Biologia do Solo/UFRRJ e à PESAGRORIO/CEPAO pelo espaço físico para a realização dos experimentos.

\section{REFERÊNCIAS BIBLIOGRÁFICAS}

1. Almeida, D. L.; Ribeiro, R. L. D.; Guerra, J. G. M. Sistema Integrado de Produção Agroecológica ("Fazendinha Agroecológica km 47”). In: $2^{\circ}$ Simpósio De Agricultura Ecológica E $1^{\circ}$ Encontro De Agricultura Orgânica, 1999, São Paulo, SP. 1999. Agricultura Ecológica. Guaíba, RS: Livraria e Editora Agropecuária Ltda. 1999, v. 2, p. 152-159.

2. Alwathnani, H. A.; Perveen, K.; Tahmaz, R.; Alhaqbani, S. Evaluation of biological control potential of locally isolated antagonist fungi against Fusarium oxysporum under in vitro and pot conditions. African Journal of Microbiology Research, Nairobi, v. 6, n. 2, p. 312-319, 2012.

3. Avendaño, C.; Rondon, W.A.G. Biological control of Phaseolus vulgaris bean vascular wilt caused by Fusarium oxysporum f. sp. phaseoli with combined Entrophospora colombiana, Trichoderma sp. and Pseudomonas fluorescens action. Agronomía Colombiana, Bogotá, v. 24, n. 1, p. 62-67, 2006.

4. Bedendo, I. P. Damping-off. In: Bergamin Filho, A.; Kimati, H.; Amorim, L. Manual de fitopatologia: princípios e conceitos. 3. ed. São Paulo: Agronômica Ceres, 1995a. v.1, cap. 42, p. 820828 .

5. Bedendo, I. P. Doenças vasculares. In: Bergamin Filho, A.; Kimati, H.; Amorim, L. Manual de fitopatologia: Princípios e conceitos. 3. ed. São Paulo: Agronômica Ceres, 1995b. v.1, cap. 44, p. 838-847.

6. Benítez, T.; Rincón, A. M.; Limón, M. C.; Codón, A. C. Biocontrol mechanisms of Trichoderma strains. International Microbiology, v. 7, n. 4, p. 249-260, 2004.

7. Bianchini, A.; Maringoni, A. C.; Carneiro, S. M. T. P. G. Doenças do feijoeiro (Phaseolus vulgaris L.). In: Kimati, H.; Amorim, L.; Bergamin Filho, A.; Camargo, L.E.A.; Rezende, J.A.M. Manual de fitopatologia: doenças de plantas cultivadas. 3. ed. São Paulo: Agronômica Ceres, 1995-1997. v. 2, cap. 34, p. 389.

8. De Cal, A.; Pascual, S.; Larena, I.; Melgarejo, P. Biological control of Fusarium oxysporum f.sp. lycopersici. Plant Pathology, London, v. 44, p. 909-917, 1995.

9. Krugner, T. L.; Bacchi, L. M. A. Fungos. In: Bergamin Filho, A.; Kimati, H.; Amorim, L. Manual de fitopatologia: princípios e conceitos. 3. ed. São Paulo: Agronômica Ceres, 1995. v.1, cap. 4, p. 85 .

10. Lewis, J. A.; Lumsden, R. D. Biocontrol of damping-off of greenhouse-grown crops caused by Rhizoctonia solani with a formulation of Trichoderma spp. Crop Protection, Philadelphia, v. 20, Issue 1, , p. 49-56, 2001.

11. Lima, L.H.C.; De MARCO, J.L.; Felix, C.R. Enzimas hidrolíticas envolvidas no controle biológico por micoparasitismo. In: Melo, I.S.; Azevedo, J.L (Ed.). Controle Biológico. Jaguariúna: Em- 
brapa Meio Ambiente, 2000. v.2, p. 263-304.

12. Lohmann, T. R.; Pazuch, D.; Stangarlin, J. R.; Selzlein, C.; Nacke, H. Seleção de isolados de Trichoderma spp. para controle de Sclerotium rolfsii em soja. Revista Brasileira de Agroecologia, Cruz Alta, v. 2, n. 2, p. 1665-1668, 2007.

13. Lucon, C.M.M. Trichoderma no controle de doenças de plantas causadas por patógenos de solo. São Paulo: Instituto Biológico, 2008. Disponível em: <http://www.biologico.sp.gov.br/artigos_ok. php?id_artigo $=77>$. Acesso em: 10 out. 2010.

14. Lucon, C. M. M.; Koike, C. M.; Ishikawa, A. I.; Patrício, F. R. A.; Harakava, R. Bioprospecção de isolados de Trichoderma spp. para o controle de Rhizoctonia solani na produção de mudas de pepino. Pesquisa agropecuária brasileira, Brasília, 44, n. 3, p. 225-232, 2009.

15. Machado, D. F. M.; Parzianello, F. R.; Da Silva, A. C. F.; Antoniolli, Z. I. Trichoderma no Brasil: o fungo e o bioagente. Revista. de Ciências Agrárias, Lisboa, v. 35, n.1, 2012

16. Melo, I. S. Agentes microbianos de controle de fungos fitopatogênicos. In: Melo, I. S.; Azevedo, J. L (Ed.). Controle Biológico. Jaguariúna: Embrapa Meio Ambiente, 1998. v. 1, p. 17-67.

17. Moreira, F. M. S.; Siqueira, J. O. Microbiologia e bioquímica do solo. Lavras: Editora UFLA, 2002. 626 p.

18. Nashwa, M. A.; Sallam; K. A. M.; Abo-Elyousr; Hassan, M.A.E. Evaluation of Trichoderma species as biocontrol agents for dam- ping-off and wilt diseases of Phaseolus vulgaris L. and efficacy of suggested formula. Egyptian Journal Phytopathology, Assiut, v. 36, n.1/2, p. 81-93, 2008.

19. Nawar, L. B. Pathological and rhizospherical studies on root-rot didease of squash in Saudi Arabia and its control. African Journal of Biotechnology, Nairobi, v. 6, n. 3, p. 219-226, 2007.

20. Pádua, R. R.; Alvarenga, D. O.; Queiroz, P. R.; Mello, S. C. M. Avaliação e caracterização de potenciais antagonistas de Sclerotium rolfsii pertencentes ao gênero Trichoderma. Brasília, DF: Embrapa Recursos Genéticos e Biotecnologia, 2007. 23 p. (Boletim de pesquisa e desenvolvimento)

21. Poddar, R. K.; Singh, D. V.; Dubey, S. C. integrated application of Trichoderma harzianum mutants and carbendazim to manage chickpea wilt (Fusarium oxysporum f.sp. ciceri). Indian Journal of Agricultural Sciences, New Delhi, v. 74, p. 346-348, 2004.

22. Santos, F. S.; Souza, P. E.; Oliveira, C. A.; Magalhães, F. H. L.; Laurenti, M. A. Ajuste do inoculo de Rhizoctonia solani em substrato para estudos de Rizoctoniose em algodoeiro e feijoeiro. Summa Phytopathologica, Botucatu, v. 31, n. 4, p. 373-375, 2005 .

23. Van Schoonhoven, A. A. S.; Pastor-Corrales, M. A. Standard system for the evaluation of bean germplasm. Cali : CIAT, 1987. 54 p. 